\title{
Designing a ranking map for the Egyptian universities according to the Egyptian context
}

Fatma El Zhraa Salem Mahmoud

Foundations of education department, Ain-Shams University, Egypt

DOI:

\begin{abstract}
Over the past ten years, the focus of Egyptian universities' interest has been the academic ranking among international universities, although there are many scientific elements that need designing an academic ranking for the Egyptian universities undergo the supervision of the Supreme Council of Universities. With the importance of international rankings such as QS, Shanghai, the New Times Rankings, and other rankings subject to the criteria of specific countries in terms of evaluating the quality of university performance, the focus of attention to having a ranking for the Egyptian universities will achieve competitiveness among Egyptian universities. It also sheds the light on Arab academic studies, which were hindered by the challenge of the English language in front of many distinguished researchers within the university system, which could reveal the importance of their studies and explorations through the expression in the mother tongue of the Egyptian society, which is Arabic language.

So, the current study aims to clarify the importance of the academic university rankings for each country according to the cultural and social context that governs each country. Therefore, the researcher relied on knowing the opinion of the other researchers and experts regarding the importance of a local academic ranking with international standards. The sample of the opinion poll was 25 male and female researchers from various universities. The researcher also prepared a map of the academic ranking of Egyptian universities based on a set of indicators that are consistent with the Egyptian context. The study ended with a set of expected scenarios when activating the map of academic rankings within the Egyptian community.
\end{abstract}

Key words: University Ranking, Egypt, Map, Context, Culture, Identity.

\section{Introduction}

Rankings are here to stay. Its real fact. For university reform normalizing the university performance is a must. The quality improvement systems are requiring many more internal enhancements and smart practices. There are many global schools of rankings and most of them serve some countries which really follow their standards especially the publication with English language and the implementation of the advanced technology.

Accordingly, countries which the main language are English can easily follow the international ranking norms, and countries such as African and 
Asian countries will face problems to be world class university otherwise if it establishes its own ranking. So, this is the idea of my research how to establish a world class university according to your own ranking systems?

Many studies declared that the university achievements based on the university identity. The university identity stems from the major community identity, and this never contradict with the multiple identities.

To clarify more, a sense of university identity creates the high internal consistency of the university and positive effects on the community context. The question is raised; why should each country create its own university ranking according to the real context?

Particularly, If the academic scientific community has a specificity that depends on society and life context, how can universities be judged from a global perspective that ignores the nature of society and reality?

Hence, these questions raise the following research questions:

1. Is there a difference between the state academic ranking of the universities and the international academic ranking?

2. What is required of Egyptian universities to follow local academic standards in line with international standards for academic ranking?

3. What is the expected scenario when establishing the Academic Prestige of the Egyptian universities in balance with international requirements?

\section{Methodology}

The method of the current paper is based on using the scenarios approach to drawing the parameters of the academic ranking of the Egyptian universities under the supervision of the Supreme Council of Universities.

\section{Literature review}

The study of Nethal K. Jajo and Jen Harrison which entitled: "world university ranking systems: an alternative approach using partial least squares path modeling" revealed how the university achievement depends on the university performance in a variety of ranking systems. So, to measure the university performance, the researchers developed an index to assess the university achievement in multiple ranking system at once. The tool which the researchers depended on was the PLS-PM (partial least squares path modelling) to develop such an index. Such tool overcoming the problems caused by the multiplicity of world university ranking systems and the diversity of indicators and standards. The researchers fostered the latent variable which is "achievement" to measure a university performance in a variety ranking systems (K. Jajo 2014).

Although the study by Miguel Antonio entitled: "the building of weak expertise: the work of global university rankers" assured that trustworthy expertise is the most important key factor in university rankings. The author focused on the concept of weak expertise to show how the weak rankers' effect on the audience. The 
researcher took THE (Times Higher Education) as a case study. The reason for this is the need to build trust and credibility (Antonio 2018).

The role of community has a fundamental impact on the university rankings. The study of Mitra Gusheh entitled. "The Creation of the UTS social impact framework: A collaborative approach for transformational change "emphasized that the holistic and systematic approach leads the universities to the world class universities and recognition of the public needs will improve the universities performances.

The author chooses the UTS (University of technology Sydney) in Australia as a case study. The study assured that rankings until recently have shown less interest in assessing the social benefits of universities. So, the study developed the UTS social impact framework. The study conclusion is the social justice, public engagement, social inclusion, participation initiations, gathering contributors with abroad range of experience and expertise from the university community, and the outreach of internal and external community all these things will lead the university to achieve the highest academic ranking (Gusheh 2019).

Another study concerns with ethics in terms of ranking to guarantee the university quality performance. The study title is "Ethics: An indispensable dimension in the university rankings" by Ali Khaki. The study focused on the principals which the present ranking systems neglect in university performances such as fairness, wisdom, ethical indicators, ethical ranking system, equality, truthfulness, law of obedient management must, professional ethics, ethical achievements, ethical assessment models (Khaki 2017).

The study of Igno Stolz which entitled, "ranking of rankings: benchmarking twenty-five higher education ranking systems in Europe" conducted a benchmarking and rank the European HRESs according to their congruence with the BPs (Berlin principals) to achieve the best practices in university performance.

The study extracted that there is a lack in what it should be and what is practiced in the universities, and the realm of ranking should be more appropriate to match the cultural context and political reality of each country to enhancing practices of HERSs (Stolz 2010).

What can be deduced from previous studies?

- Most of the studies concentrate on the university context in terms of rankings and performance assessment.

- The ethical factor should be more effective in the global university systems of ranking.

- The great effect of the community on the university social work and community participation impact on the university achievements.

- The need to unify the academic world ranking patterns universities in index or framework for universities to avoid the consequences of the multiple academic ranking systems of universities. 


\section{The first question}

Is there a difference between the state academic ranking of the universities and the international academic ranking?

To answer this question, it is important to know that there is no single global academic ranking but rather many academic rankings. And all these HERSs not achieve congruence overall and serve specific cultures and principles (Stolz 2010).

So, if each country creates its own university rankings this will achieve many things for instance:

1. Maintain on its scientific spirit and identity.

2. The processes of evaluation and reflection are very easy.

3. The monitoring and the follow up system will achieve comprehensively.

4. The supreme council of universities will have fundamental role in keeping standards in action and smart practices.

5. The state academic rankings of the universities can easily transfer the experiences into the other development domains.

6. The language challenges to express on the ideas and solutions will recede.

7. The success of the state university ranking map will move it to be global rankings and the Arab universities can use it.

To assess the need to Egyptian university ranking the researcher conducted a survey for 25 staff members form differ universities and the result was the following:

The study sample: The researcher targeted different fields of study and universities to know their point of view according to their specialties. Six members specialized in education, three specialized in humanities, four members specialized in information communication technology, five members specialized in science, three members specialized in engineering, two members specialized in the economy and more two members specialized in medicine. The study sample varied to include Ain Shams, Kafr El Sheikh, Zagazig, Sohag and Cairo universities.

\section{Field of study}

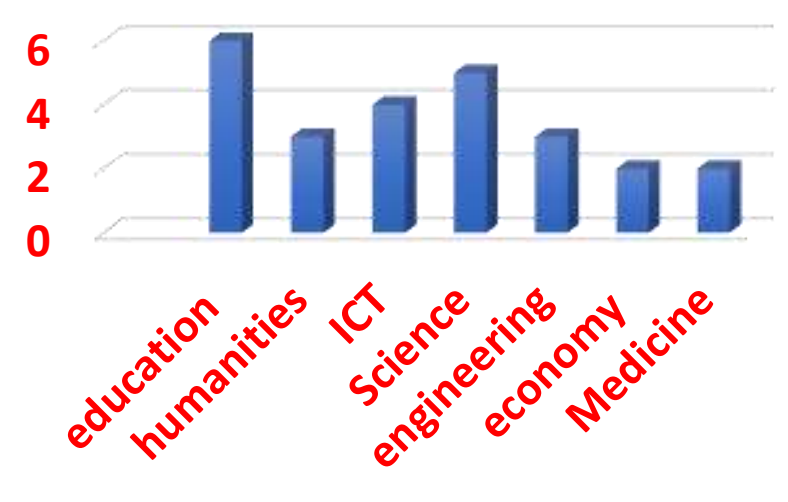

Fig. (1)

\section{Survey questions}

The first question was about: which language do you prefer to write your research paper?

When asking them about the reasons behind that the researchers who preferred to write their academic papers in Arabic agreed that Arabic language expresses on their identities, and they can easily express on their ideas and proposals through the national language. Most of these researchers' studies art, education, humanistic science.

On the other hand, the researchers who preferred to write their academic papers in other languages agreed that they need their papers be international 
and be spared all over the world. Most of these researchers their studies already with English language such as who studies sciences, ICT, engineering, medicine.

\section{Which language do you prefere to write your research paper?}

$100 \%$

$0 \%$

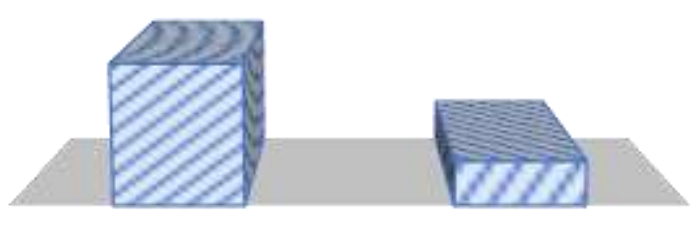

\section{Arabic Foreign Lang.}

Fig. (2)

The second question was about What are the most important difficulties that you find in international publishing?

The responses were $64 \%$ answered difficulty of international publishing regulations, $24 \%$ answered difficulty understanding the foreigners, $12 \%$ answered the difficulty of writing with English language.

\section{What are the most important difficulties that you find in international publishing ?}

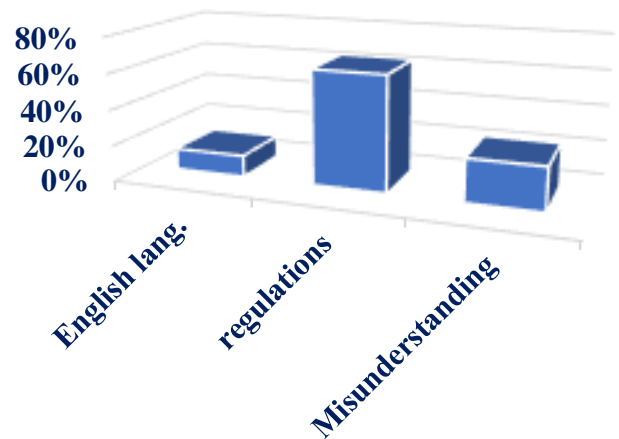

Fig. (3)
The third question was about Which do you prefer in evaluating your scientific research, Arab or foreign reviewer?

The responses were $40 \%$ were the percentage of those favoring the Arab reviewers and the neutral ones with whom the nationality of the reviewer is not differentiated. While $20 \%$ of the respondents preferred the foreign reviewers and described them as more objective.

\section{Which do you prefer the arabic or forigner reviewer in evaluating your research paper?}

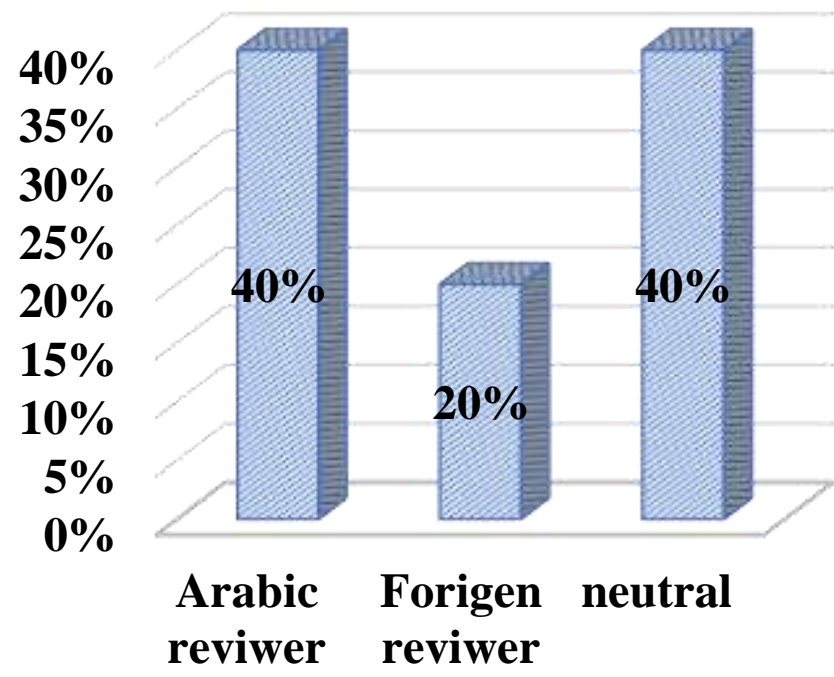

Fig. (4)

The fourth question about If your research is translated into multiple languages after writing it in Arabic, would you prefer to publish it in Arabic or foreign?

The responses were about $76 \%$ preferred translated their academic research into foreign language, although $24 \%$ preferred the Arabic language. 
The fifth question was about; If the academic rankings standards for universities become Egyptian, will this affect the excellence of Egyptian universities?
The responses were $28 \%$ answered with sure, $20 \%$ answered it is not a requirement, $16 \%$ responded Standards are to be global, and $36 \%$ answered that they prefer the global rankings.

If your reseach is translated into multiple languages after writing in arabic, would you prefer to publish it in Arabic or foreign language?

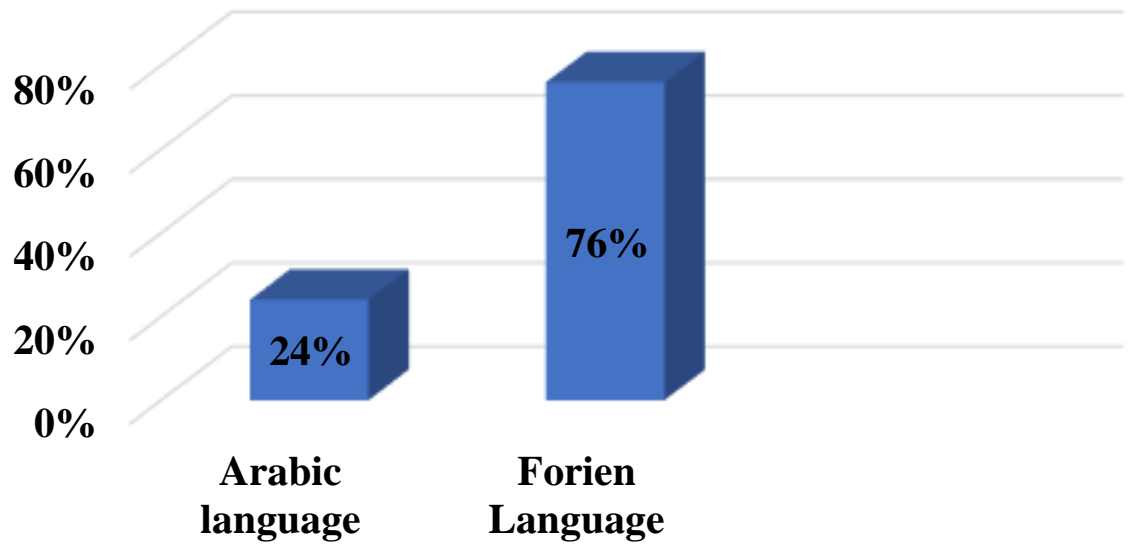

Fig. (5)

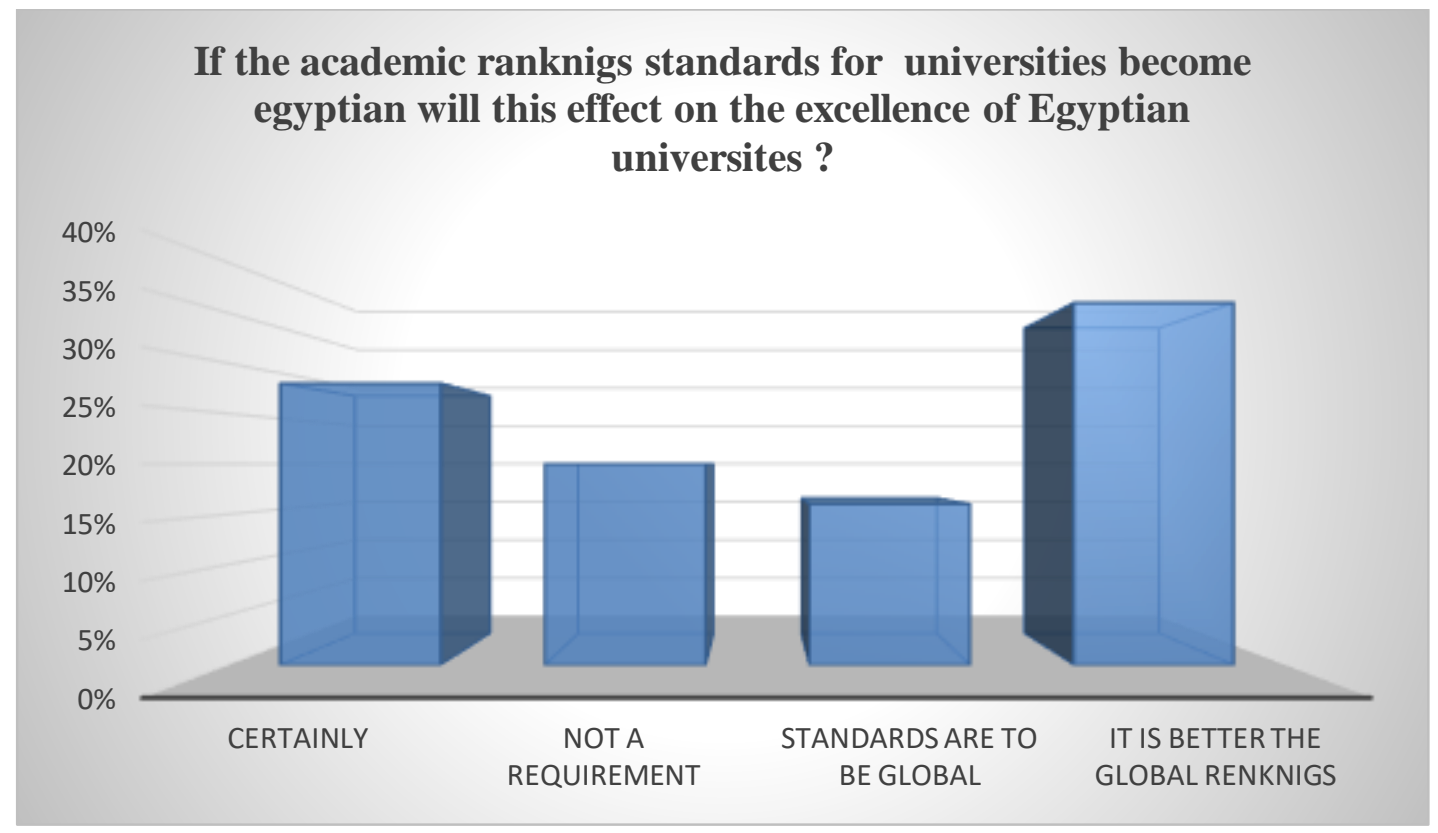

Fig. (6)

The six question was about; What is your opinion provided that the criteria were of a global nature, on what is said that publishing in mother tongue expresses the identity of the Egyptian Arab community?

The percentage of those who agreed was equal, and the percentage was $40 \%$. However, $20 \%$ of the respondents said that there is no relationship between scientific publishing and cultural identity. 


\section{what is your opinion of what is said that publishing in mother tongue expresses the identity of the Egyptian Arab community \\ ?}

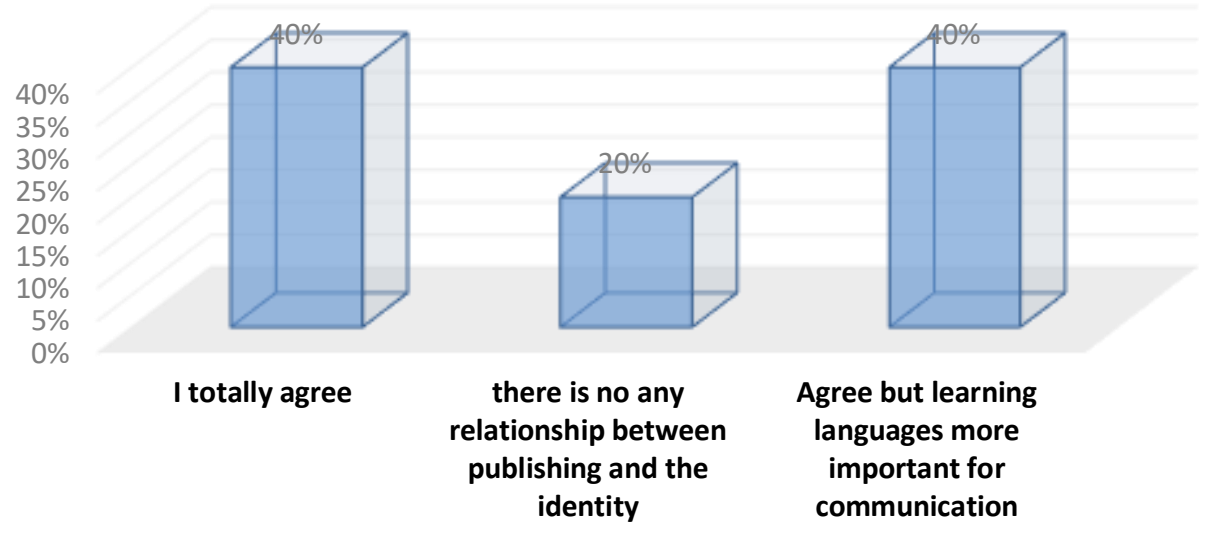

Fig. (7)

Critical analysis: It is evident that many of the responses are characterized by the following:

Firstly, the difficult conditions and rules for international publishing cause many researchers to refrain from international publishing.

Secondly: Many researchers prefer to express themselves in Arabic, which expresses their identity and societies. However, if translation into other languages is available, this will be better for international publication.

Third, international evaluation is better than local review for research, according to the researchers 'opinion, as it is more objective.

Fourth, the desire of the most researchers from among the sample members to publish internationally in another language, but research and linguistic complexities represent a major obstacle.

Sixth, International standards for ranking is very important for researchers, whether academic ranking is Egyptian or international.

\section{The second question}

What is required of Egyptian universities to follow local academic standards in line with international standards for academic ranking?

There is a firm conviction that all the criteria and indicators of the academic ranking of universities are continuous and advanced efforts to reach the optimal performance of the universities to coming up with the global performance.

Therefore, any local efforts exerted must keep pace with global efforts in this regard, due to the considerations of global communication and the confirmation of global projects among universities of the whole world. This doesn't contradict with the existence of special academic standards for Egyptian universities that correspond to the culture and needs of the academic community and the Egyptian context. 
Table (1): The following matrix shows the key pillars for some international academic rankings.

\begin{tabular}{|c|c|c|}
\hline Ranking & \multicolumn{2}{|c|}{ Pilers \% } \\
\hline \multirow{4}{*}{ 1. ARWU } & 1-quality of education. & $30 \%$ \\
\hline & 2-quality of faculty & $40 \%$ \\
\hline & 3-reasearch output. & $20 \%$ \\
\hline & 4-Percapita performance. & $10 \%$ \\
\hline \multirow{6}{*}{ 2. QS } & 1-Academic reputation & $40 \%$ \\
\hline & 2-employe reputation & $10 \%$ \\
\hline & 3-faculty student ratio & $20 \%$ \\
\hline & 4-citations per faculty & $20 \%$ \\
\hline & 5-international faculty ratio & $5 \%$ \\
\hline & 6-international student ratio & $5 \%$ \\
\hline \multirow{5}{*}{$\begin{array}{l}\text { 3. THE; Times } \\
\text { higher education }\end{array}$} & 1-Teaching & $30 \%$ \\
\hline & 2-Research & $30 \%$ \\
\hline & 3-Citations & $30 \%$ \\
\hline & 4-international outlook & 7.5 \\
\hline & 5-industry income & 2.5 \\
\hline
\end{tabular}

The following two notes from the previous table:

- The great similarity between the international academic rankings.

- Academic rankings confirm the university's societal impact through the education return component and the quality of the graduate's performance.

After the opinion poll, the following requirements can be determined to establish academic standards for the academic ranking of the Egyptian universities with international standards:

The first requirement: an in-depth study of the contexts of Egyptian universities.

The second requirement: the creation of an academic partnership between the Egyptian governmental and private universities.
The third requirement: full supervision by the Supreme Council of Universities over the ranking of the Egyptian universities according to the agreed academic rankings.

Based on the above, a map of the academic ranking criteria for Egyptian universities can be designed as follows:

\section{The ranking map for the Egyptian universities}

The map consists of five main elements:

\section{The first component: teaching (20\%)}

It consists of the following indicators:

- The first indicator: Teaching methods (5\%)

- The second indicator: Teaching activities $(5 \%)$

- The third indicator: Staff members achievement files (2.5\%).

- The fourth indicator: Student achievement files $(2.5 \%)$. 
- The fifth indicator: Evaluation methods $(5 \%)$.

The second component is the scientific research $(30 \%)$

It consists of many measurement indicators:

- The first indicator: scientific publication. $(6 \%)$.

- The second indicator: the percentage of citations $(6 \%)$.
- The third indicator: the scientific values of the scientific periodicals in Egyptian universities (6\%).

- Fourth indicator: the practical value of master's and doctoral theses $(6 \%)$.

- Fifth indicator: the rate of scientific production compared to other universities. $(6 \%)$.

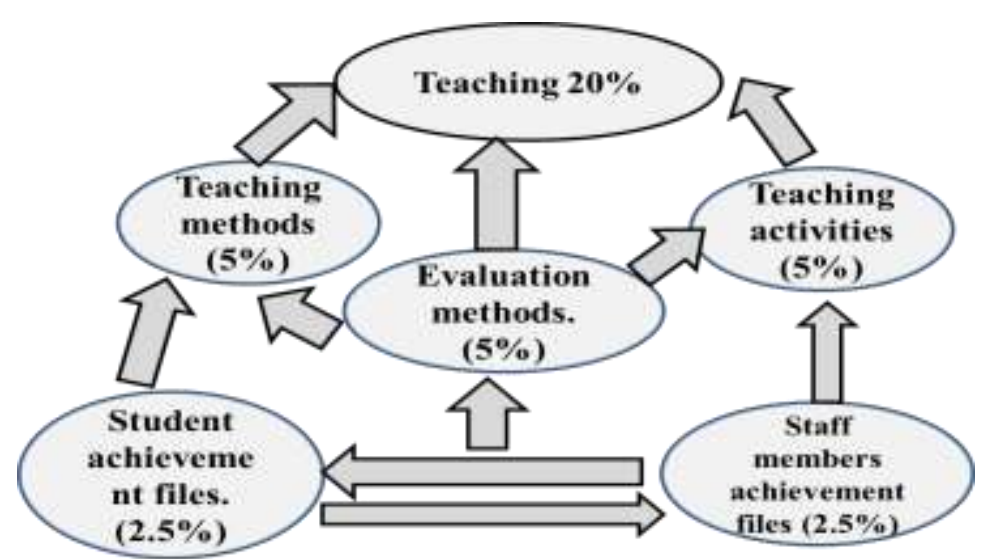

Shape (1)

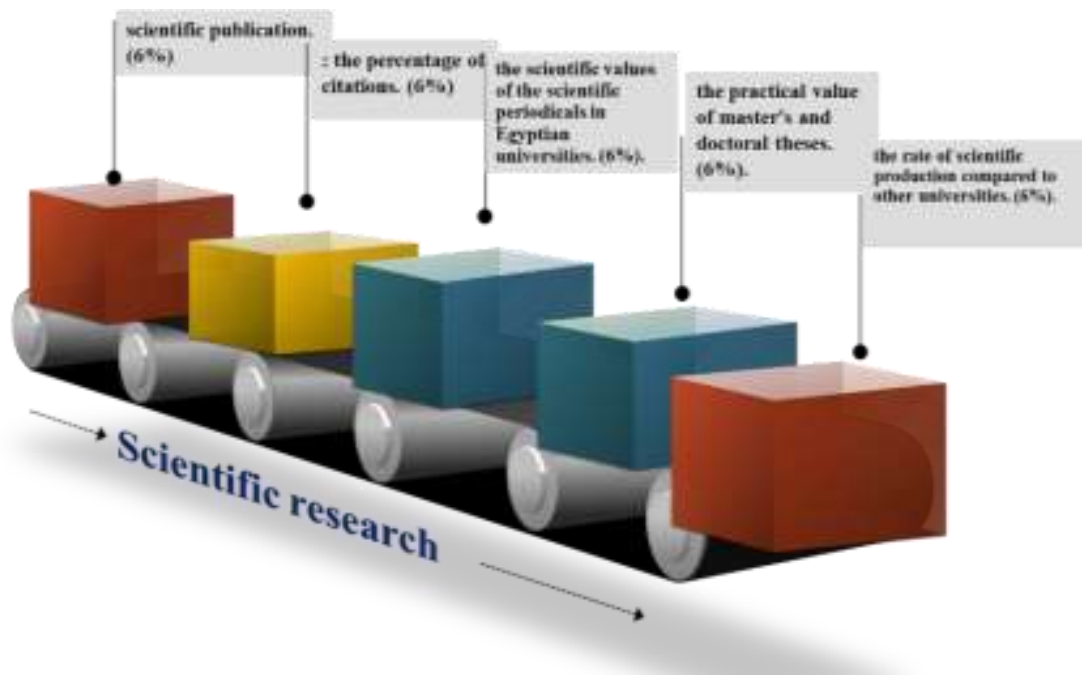

Shape (2)

\section{The university performance $25 \%$}

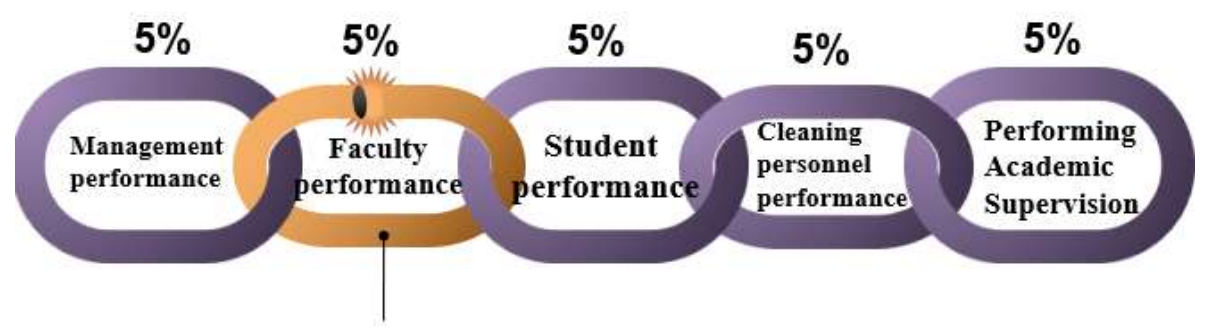

Shape (3) 
The third component, the university - Indicator 1: university annual projects 5\%. performance, $25 \%$

It includes the following indicators:

- First indicator: Management performance $5 \%$

- Second indicator Faculty performance 5\%

- $\quad$ Third indicator Student performance 5\%

- Forth indicator: cleaning personnel performance $5 \%$

- Fifth indicator: Performing Academic Supervision $5 \%$

\section{The fourth component: entrepreneurship $15 \%$}

This includes the following indicators:

- Indictor 2: university community serves $5 \%$

- Indicator3: university industrial, medical, educational, technical projects $5 \%$.

\section{The fifth component: Environmental} development. $10 \%$

This includes the following indicators:

- Indicator 1: environmental field studies 3\%.

- Indicator 2: eco biodiversity preservation $3 \%$.

- Indicator 3: eco projects $2 \%$.

- Indicator 4: Student environmental engagement $2 \%$.

The fourth component: entrepreneurship $15^{\circ} \mathrm{o}$

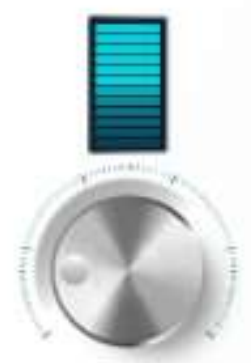

$5 \%$

Cniversity annual projects

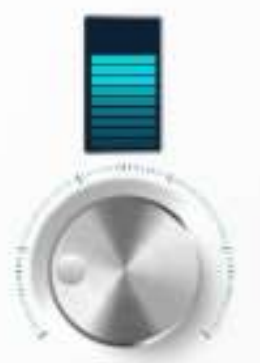

$5 \%$

University community serves

Shape (4)

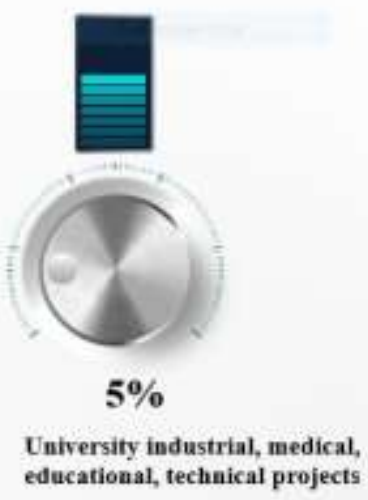

Environmental field studies. $3 \%$

The fifth component: Environmental development. $10 \%$

Eco projects.

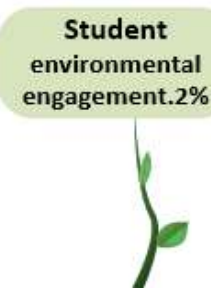

$2 \%$

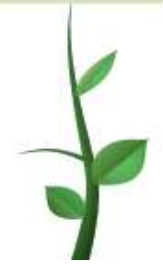

Eco biodiversity preservation. $3 \%$

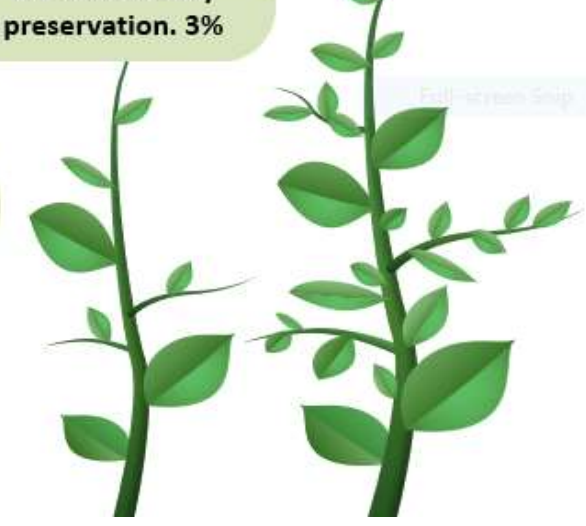

Shape (5) 
The following matrix covers all these components

\begin{tabular}{|c|c|c|c|c|c|c|}
\hline \multirow{7}{*}{$\begin{array}{c}\text { The } \\
\text { indicator }\end{array}$} & \multicolumn{5}{|c|}{ The Egyptian university ranking map } & \multirow{7}{*}{$100 \%$} \\
\hline & $\begin{array}{c}\text { Teaching } \\
(20 \%)\end{array}$ & $\begin{array}{c}\text { Scientific } \\
\text { research }(30 \%)\end{array}$ & $\begin{array}{c}\text { The university } \\
\text { performance, } \\
25 \%\end{array}$ & $\begin{array}{c}\text { Entrepreneurship } \\
15 \%\end{array}$ & $\begin{array}{c}\text { Environmental } \\
\text { development } \\
10 \%\end{array}$ & \\
\hline & $\begin{array}{c}\text { Teaching } \\
\text { methods }(5 \%)\end{array}$ & $\begin{array}{c}\text { Scientific } \\
\text { publication } \\
(6 \%)\end{array}$ & $\begin{array}{c}\text { Management } \\
\text { performance 5\% }\end{array}$ & $\begin{array}{c}\text { University annual } \\
\text { projects. } 5 \%\end{array}$ & $\begin{array}{c}\text { Environmental } \\
\text { field studies } \\
\mathbf{3 \%} .\end{array}$ & \\
\hline & $\begin{array}{c}\text { Teaching } \\
\text { activities }(5 \%)\end{array}$ & $\begin{array}{c}\text { the percentage } \\
\text { of citations } \\
(6 \%)\end{array}$ & $\begin{array}{c}\text { Faculty } \\
\text { performance } \\
5 \%\end{array}$ & $\begin{array}{c}\text { University } \\
\text { community serves } \\
5 \%\end{array}$ & $\begin{array}{c}\text { ecobiodiversity } \\
\text { preservation } \\
\mathbf{3 \%}\end{array}$ & \\
\hline & $\begin{array}{l}\text { Staff members } \\
\text { achievement } \\
\text { files }(2.5 \%)\end{array}$ & $\begin{array}{l}\text { The scientific } \\
\text { values of the } \\
\text { scientific } \\
\text { periodicals in } \\
\text { Egyptian } \\
\text { universities } \\
(6 \%) .\end{array}$ & $\begin{array}{c}\text { Student } \\
\text { performance 5\% }\end{array}$ & \multirow{3}{*}{$\begin{array}{c}\text { University industrial, } \\
\text { medical, educational, } \\
\text { technical projects. } \\
5 \%\end{array}$} & $\begin{array}{c}\text { Eco projects. } \\
2 \%\end{array}$ & \\
\hline & $\begin{array}{c}\text { Student } \\
\text { achievement } \\
\text { files. }(2.5 \%)\end{array}$ & $\begin{array}{c}\text { The practical } \\
\text { value of } \\
\text { master's and } \\
\text { doctoral theses. } \\
(6 \%)\end{array}$ & $\begin{array}{c}\text { Cleaning } \\
\text { personnel } \\
\text { performance 5\% }\end{array}$ & & $\begin{array}{c}\text { Student } \\
\text { environmental }\end{array}$ & \\
\hline & $\begin{array}{c}\text { Evaluation } \\
\text { methods. (5\%) }\end{array}$ & $\begin{array}{l}\text { The rate of } \\
\text { scientific } \\
\text { production } \\
\text { compared to } \\
\text { other } \\
\text { universities. } \\
(6 \%) .\end{array}$ & $\begin{array}{c}\text { Performing } \\
\text { Academic } \\
\text { Supervision 5\% }\end{array}$ & & $\begin{array}{c}\text { engagement } \\
\mathbf{2 \%}\end{array}$ & \\
\hline
\end{tabular}

\section{The third question}

What is the expected scenario when establishing the Academic Prestige for the Egyptian universities in balance with international requirements?

For fulfilling the previous ranking map, Egyptian universities one of the following scenarios could occur:

1- Meta-evaluation of universities scenario.

4. Global competitiveness scenario through national academic standards map.

2- Scenario of many countries adopting the academic standards map.
The first scenario: Meta-evaluation of universities

Universities need specific mechanisms for selfsteering based on continuous criticism of practices within the university. Pachko explained the importance of meta-evaluation for continuous improvement of university performance. The meta-evaluation process also requires metacriteria. (Pachko 2009, 17).

David Tee' study also emphasized the importance of evidence-based training, considering psychological training, especially the idea of selfesteem, and dealing objectively with the self during performance self-evaluation, and the 
existence of an evaluation scale to attain the institution's goal. (Tee 2019, 48).

The meta-evaluation scenario refers to adopting a new evaluation philosophy based on integration and not partial evaluation of the organization. In the sense of relying on comprehensive evaluation criteria that are in-depth in analyzing the institutional performance, starting from the performance of the clean worker, passing through the administrative structure, administrative leaders, faculty members, content and assessment systems, to the evaluation of the final product during its interactions within the community.

The following probabilities can be expected for a meta-evaluation scenario:

- The first probability: canceling the idea of degrees and replacing it with the idea of capabilities.

- The second probability: reliance on actual performance, not oral or written performance.

- The third probability: producing measures to evaluate performance that are based on the comprehensiveness of qualifications, institutional capabilities, and production rates.

\section{The second scenario: Global competitiveness}

\section{through national academic standards map.}

Jelena and Leopold believe that the proliferation of universities academic ranking in many countries has resulted in a kind of competition that extends not only between universities, but between academic rankings of universities every year. And contextual dimensions began to enter the academic ranking of universities, such as the university social construction and new conditions for controlling university performance. So, it is obvious the social process through which rankings affect competition. (Jelena 2018, 275276).

According to what has been suggested of ranking map standards in the previous pages, it can be expected that a competition will arise between Egyptian universities in order to achieve these standards or to set specific indicators to each university for distinguish itself from other universities. This automatically raises the academic ranking of universities and achieves the country's goals in academic excellence for universities at the local and global levels.

Another area of concern which the global competitiveness report 2020 refers to is the digitalization transformation after the COVID- 19 pandemic and how the communities offer greater digitalization public services (Global competitiveness report 2020). This rapid digital transformation of all state institutions, especially educational institutions, which requires a parallel mental transformation and the ingenious ability of university and administrative leaders, faculty members and students to adapt to the transformation to the corner of distance learning, holding meetings and practicing all the activities from a distance in order to ensure social distancing and the preservation of the others' lives.

The following probabilities can be expected for global competitiveness through national academic standards map scenario: 
- The first probability: achieving global competitiveness by following Egyptian university academic ranking that competes with other international academic ranking.

- The second probability: the intense focus on university digitization more than the concept of a regular university.

- The third probability: university competition to prepare scientific research that serves society and the environment to achieve the highest competitive advantage.

\section{Third Scenario: many countries adopting the} academic standards map.

The idea of many countries adopting the Egyptian university standards for the academic ranking according to what has been prepared from a map of the academic ranking. This is the most likely scenario in the case of the success of the Egyptian standards and their conformity with the international academic standards, and their ability to reach universities to the level of global competitiveness.

Hence, there is no preference for an academic ranking over another in this case, but rather what is closer to application and serves universities to obtain the best performance that contributes to the advancement of society in its various sectors.

The following probabilities can be expected for many countries adopting the academic standards map.

- The first probability: forming unified standards for academic ranking at the level of Middle Eastern countries.
- The second probability: anticipating best practices from different university contexts for multiple countries.

- The third probability: the formation of a unified technological network for communication to follow up and evaluate university performance in the countries participating in the academic ranking.

All measures taken to realize these scenarios will be under the leadership of the Supreme Council of Egyptian Universities.

\section{Conclusion}

The study extracted that increasing the scientific productivity of universities can occur distinctively by designing a map of the academic ranking that is consistent with the cultural and social contexts and is consistent with the global academic ranking.

The study clarified a set of expected scenarios based on the adoption a map of the academic ranking for Egyptian universities. The study relied on the design map and laws for academic ranking on five components Teaching, Scientific Research, Entrepreneurship, University Performance and Environmental Development.

So, the following points are the main conclusion of the study:

- The Egyptian universities can set academic rankings with international standards and Arab characteristics.

- The academic standards of Egyptian universities can be matched with international standards. 
- The Supreme Council of Universities can directly supervise the performance of Egyptian universities through the academic ranking map.

- The Egyptian universities ranking internationally does not contradict the academic Egyptian ranking of universities.

- Egyptian universities ranking preserves the Arab identity that the Egyptian society enjoys in highlighting its scientific research and achievements in a language known to the people of the East and understood by the Arab entity.

- Many universities in the Arab countries can adopt the Egyptian universities academic ranking and make twinning with the Supreme Council of Egyptian Universities.

- The cultural reality and the applied context vary from one country to another. That is why the existence of academic ranking standards linked to Arab countries increases the scientific productivity of Arab universities.

\section{Recommendations}

First: Linking the performance of Egyptian universities with Arab universities in a unified academic ranking.

Second: Guidance by international standards in the academic ranking.

Third: International monitoring by the participating universities when implementing standards for improving academic performance.
Fourth: Arab universities' partnership in scientific research journals in Arabic, English, and French. Fifth: Establish effective mechanisms to address all the challenges that stand in the way of achieving an advanced position in the Arab rankings.

sixth: Establishing virtual universities targeting more employment in information and communication technology.

Seventh: Official universities in Arab countries communicate with virtual universities to achieve blended learning.

eighth: Evaluating the Arabic academic ranking experience through international organizations for institutional evaluation.

Ninth: continuous accounting, measuring academic productivity and its effects on community development.

Tenth: Study the status of productivity of Arab women in universities and compare them with foreign countries.

Eleventh: Measuring the extent of Arab universities 'interest in environmental issues and space sciences.

Twelfth: Seeking the help of experts from foreign countries in evaluating the Arab experience in the field of academic arrangement.

Thirteenth: Evaluating the success of entrepreneurship and enterprises in Arab universities, and the added value behind it.

Fourteenth: Study the extent of employee satisfaction in Arab universities and link it to their scientific productivity. 
Fifteenth: Evaluate the extent to which the annual executive plans are achieved within universities. Sixteenth: Evaluate the extent of spending the imposed budget each year, and the destinations of spending in accordance with the financial plan.

Seventeenth: To assess the extent to which the target groups benefit from the budget every year.

Eighteenth: Study the extent of students 'and graduates' satisfaction with the services provided within Arab universities.

Nineteenth: Study the extent of Arab universities 'interest in the social, philosophical and educational humanities.

Twentieth: Study the role of Arab universities in exploring alternative and renewable resources in order to serve society and the environment.

Twenty-first: Evaluating the level of hygiene within Arab universities, and the satisfaction of faculty, staff and students with it.

Twenty-second: A study of the mental, physical, and nutritional health of the academic community, and its effects on the sustainable development of Arab countries.

Twenty-third: Evaluating the scholarships granted to poor students within Arab countries, and their role in raising the academic ranking of Arab universities.

\section{Acknowledgements}

The researcher thanks his academic institution, Ain Shams University, and all those who contributed to the opinion poll.

\section{References}

Abd El Haleem Hanan, 2016. technological business incubators and research projects management in the Egyptian universities, Ain Shams University, faculty of education, Egypt.

Antonio Miguel, 2018. the building of weak expertise: the work of global university rankers, High education, No.75, UK, Pp 415-430.

Gusheh Mitra et al., 2019. The Creation of the UTS social impact framework: A collaborative approach for transformational change, international journal of community research and engagement, V.12, No.2, Austalia, Pp 1:23.

Global competitiveness report, 2020. How countries are performing on the road to recovery, world economic forum, Switzerland.

Jelena Brankovic et al., 2018. how rankings produce competition: the case of global university rankings, Vol.47(4), Germany, 270-288.

K. Jajo, Nethal, Harrison Jen, 2014. world university ranking systems: an alternative approach using partial least squares path modeling, journal of higher education policy and management, Vol.36(5), Routledge, UK, Pp 471-482.

Khaki Ali, 2017. The study's title is "Ethics: An indispensable dimension in the university rankings, Sci Eng ethics, No.23, USA, Pp 65-80.

Pachko Enrique, et al., 2009. Quality criteria for self -valuation in higher education, Jmde, journal of multidisplinary evaluation, Vol.6, No.11, Spain, Pp16-31. 
Stolz Ingo et al., 2010. ranking of rankings benchmarking twenty -five higher education ranking system in Europe, high educ, No.60, USA, Pp 507-528.

Stolz Igno et al., 2010. ranking of rankings: benchmarking twenty five higher education ranking systems in Europe, High Edu, No.60, Springer, USA, Pp 507-528.

Salem Fatma El Zhraa, 2017. Using education based planning approach in establishing the university code of practice for the higher education quality assurance, educational review, Vol.1, No.41, Ain Shams university, Egypt, Pp 303-334.

(2017). building a trustworthy higher education system according to the global university rankings (futuristic study), the Arab
National Higher education conference towards global competitiveness, university of Jordan, Jordan.

(2020). The educational effects of social distancing considering the pandemic of COVID19, educational review, Suhag, Egypt, Pp 1-23. DOI: 10.12816/edusohag.2020.96944

Tee David et al., 2019. Goal attainment scaling and coaching client core self-evaluations, the coaching psychologist, Vol.15, No.1, UK, 47-54.

THE, 2021. world university ranking methodology, times higher education, USA.

University of Edinburgh 2016. code of practice for supervisors and research students, university of Edinburgh, UK. 